\title{
WISC-R Information and Digit Span Scores of American and Canadian Children
}

\author{
David P. Beauchamp \\ State University of New York, Plattsburgh \\ Douglas D. Samuels \\ William Paterson College of New Jersey \\ Robert J. Griffore \\ Michigan State University
}

\begin{abstract}
This study investigated differences in performance between third-grade American and Canadian children on two subtests of the Wechsler Intelligence Scale for Children-Revised (WISC-R). The Information subtest, which is culturally laden, and the Digit Span subtest, which is less subject to cultural factors, were administered to 30 American and 30 Canadian children. Mean Information scores in the two groups were not significantly different, but Canadian children scored significantly higher on Digit Span. This difference was attributable to their higher mean score on Digit Span Forward. Canadian and American Digit Span Backward mean scores did not differ. Results are discussed in terms of Canadian and American educational and test-taking experiences.
\end{abstract}

American influences on Canadian education have long been extensive, or perhaps, as some would maintain, excessive. As two examples of the American influence on Canadians, Canadian professionals have pursued their graduate and professional training in the United States (Welboum, 1972), and the number of American textbooks used in Canadian schools has risen to a level which some find alarming (Katz, 1974). But an example which may predictably stimulate at least a moderate degree of attention by Canadian educators and scholars has been the use of American standardized tests. such as the

APPLIED PSYCHOLOGICAL MEASUREMENT

Vol. 3. No. 2 Spring 1979 pp. 231-236

(c) Copyright 1978 West Publishing Co.
Wechsler Intelligence Scale For Children-Revised (WISC-R) with Canadian children. Since this test was standardized on a sample of American children, the validity of the test might be questioned when used with Canadian children. Though the similarities between American and Canadian society are obviously great, it cannot be ignored that each of these countries has a distinctly different heritage and that these heritages have led to the development of their respective cultures.

Numerous arguments against the use of standard intelligence tests with culturally diverse populations have appeared (Anastasi, 1967, 1976; Liddle, 1967, pp. 488-522; Williams, 1970). A work group of the Society for the Psychological Study of Social Issues (Division 9 of the American Psychological Association) presented a sound discussion of some of the issues involved in the use of current standardized tests with culturally diverse children (Deutsch, Fishman, Kogan, North, \& Whiteman, 1964; Sattler, 1974).

Although Canada is considered to be bicultural, it is, in reality, a multicultural society. Approximately $45 \%$ of the population are British in origin and $30 \%$ are French. The remaining $25 \%$ represent a mosaic of countries around the world (Census of Canada, 1971). The classrooms of Canada, with few exceptions, con- 
tain a cross-section of several of these cultural groups (Katz, 1974).

Bilingualism in Canadian society is very noticeable, particularly in Quebec, where French is the dominant language. Advertising, road signs, and all government forms, for example, are written in both French and English.

Despite the fact that the WISC-R was standardized on the United States population, the utilization of this test with Canadian children is widespread throughout the Englishspeaking school system. Research is needed to investigate cross-cultural differences between Canadian and American children on the Wechsler Intelligence Scale for Children-Revised (WISC-R). School psychologists' evaluations and remedial recommendations are formed on the basis of subtest and overall performance. In both cases, the effects of cultural milieu should be taken into account when assessing a child's abilities.

The WISC-R Information subtest was designed to assess what the child has learned from his/her home and school experiences. Research has indicated that the subtest is influenced by cultural background and is highly representative of information typically $\mathrm{em}$ phasized in American schools (Glasser \& Zim. merman, 1967). Since achievement on this subtest is dependent on the general knowledge the average American child usually acquires in his/her everyday environment, it is reasonable to expect that American children's performance on this subtest may be significantly higher than their Canadian counterparts. It may also be expected, if cultural differences do exist, that this WISC-R subtest includes culturally biased questions. These questions will result in the American subjects' obtaining significantly higher mean scores on specific "culturally unfair" questions, which will contribute to differences in overall performance between Canadian and American children.

On the WISC-R, the items are placed in order of increasing difficulty, based on the test's standardization on 2,200 American children between December 1971 and January 1973. It is likely that the percentage of correct responses of American subjects will follow the difficulty gradient more closely than those of the Canadian subjects. Generally, the Canadian subjects might be expected to show more scatter in their performance due to the differences in their cultural experiences.

The WISC-R Digit Span subtest is one on which children's performance may be least affected by cultural variables (Jensen, 1970, pp. 53-101). The subtest consists of sections requiring a repetition of "digits forward" or "digits backwards." The subtest requires a child to orient his or her attention to this task fully. Since the Digit Span subtest is less subject to cultural factors, it may be expected that overall performance between the American and Canadian subjects might not differ significantly. However, some research (Sattler, 1974; Anastasi, 1976) has indicated that a child's motivation and ability to orient attention toward a given task is influenced by his/her cultural background. Nonetheless, the Digit Span subtest is useful for investigating the possibility of nonverbal cultural differences, such as attention, that may influence performance on the WISC-R.

The purpose of the present study was to investigate cross-cultural differences in performance between Canadian and American children on two subtests from the WISC-R: Information and Digit Span, both forward and backward.

\section{Method}

\section{Subjects}

A total of 60 subjects were involved in the study. Thirty children were enrolled in a third grade English-speaking elementary class in Hemmingford, Quebec. Another 30 children were enrolled in a third grade elementary class in Peru, New York. Both schools are located in rural areas, approximately 45 miles apart. Dis- 
tance from metropolitan areas (Montreal, Quebec, and Plattsburgh, N. Y.) are comparable. Both classes were taught by male teachers. Average chronological age in the Peru class was eight years, ten months; and in the Hemmingford class, nine years, zero months.

\section{Instruments}

Two subtests from the Wechsler Intelligence Scale for Children-Revised were utilized. Information and Digit Span were selected because they were considered the most relevant subtests for the study's design. Also utilized were the WISC-R test manual (Wechsler, 1974); WISC-R answer sheets; and a quiet, isolated testing room with a small desk and two chairs.

\section{Procedure}

Tests were administered individually to each subject by the same examiner. All data were collected toward the end of the academic semester in April. Classes were equal in size, and all children in each class were tested. The examiner initially briefed each class on the purpose of the testing by saying, "I am trying to find out how third graders learn, and I would like to have each of you come down and answer some questions for me." Subjects then drew random numbers from a box and proceeded to the testing room in numerical order.

The Information subtest was administered first. The test consists of 30 verbal questions which the subject can usually answer with a simply stated fact. Administration and scoring followed standardized procedures described in the WISC-R manual except that instead of starting and stopping at basal and ceiling levels, all questions were asked. Following the Information subtest, the Digit Span subtest was administered. In this subtest the examiner presents sequences of numbers which the subjects repeat either in the same order or in reverse order. Administration and scoring followed standardized procedures described in WISC-R manual.
The average time required to administer the tests to each child was approximately 15 minutes.

\section{Results}

The questions on the Information subtest were based on the general knowledge that the average American child could acquire from his/her everyday environment. It was hypothesized that due to differences in the Canadian culture, certain items were culturally biased, and American subjects' overall performance scores would be significantly greater than their Canadian counterparts. It was also hypothesized that the Digit Span subtest would not be influenced by cultural factors, and no significant differences between overall performance scores was expected.

Sample means were calculated from both groups' individual performance scores on the two subtests, and $t$-tests for independent random samples were calculated. Table 1 presents the results of the analysis.

Contrary to the hypothesis, the difference between the mean performance scores on the Information subtest was not significant. These results do not support the hypothesis that Canadian children's performance on the subtest is limited by cultural factors.

The results of the Digit Span analysis were also contrary to expectations. Canadian children's mean performance score on this subtest was significantly higher than that of the American children. Further analysis showed the difference was due mainly to a significantly higher mean score on the Digits Forward section of the subtest. The difference between the performance means on the Digits Backward section was not significant. This suggests there are cultural differences in the way American and Canadian children attend or orient themselves to a task such as this.

On the Information subtest, a progressively lower percent correct should be obtained as the difficulty of the question increases. It was found, 
however, that neither the American nor the Canadian children's pattern of responses followed this expected gradient. On the first 11 of the 30 questions, the percentage correct ranged from 70 to 100. But then for Question 12 through Question 15, the percentage correct dropped abruptly to 10 . Through Question 21, the percentage correct ranged between 0 and 15 . With the exception of Question 22, on which the American and Canadian percentages correct were 25 and 45, respectively, the percentage correct on each of the remaining questions was 0 . There was, overall, much similarity between the two groups.

Although overall performance on the Information subtest was not found to be significantly different between American and Canadian subjects, an analysis was conducted to determine if there were specific questions on the subtest that might be influenced by cultural differences. To investigate this, a chi-square was utilized to determine whether the responses obtained on specific questions departed significantly from what was expected.

Results indicated that certain questions on the Information subtest did differ from expectations. Question 5, "How many pennies make a nickel?" $\left[\chi^{2}(1)=12.0, p<.001\right]$; Question 16, "Who invented the electric light bulb?" $\left[\chi^{2}(1)=\right.$ $10.0, p<.01]$; and Question 21, "In what continent is Chile?" $\left[\chi^{2}(1)=10.0, p<.01\right\}$ were answered correctly more often by American children than by their Canadian counterparts. On the other hand, Question 13, "What does the stomach do?" $\left[\chi^{2}(1)=10.0, p<.01\right]$ was more frequently answered correctly by Canadian children. These responses reflect differences in cultural experiences and give support to the hypothesis that cultural differences influence performance on certain WISC-R questions.

\section{Discussion}

Although the present study is limited because of its small sample size and because students in only one American and one Canadian classroom were tested, the findings are suggestive of some possible cultural differences relative to WISC-R performance. Although specific questions on the Information subtest were found to be culturally biased for Canadian subjects, there were also questions on which the Canadian subjects scored significantly better than their American counterparts. Results indicated the American and Canadian subjects did not differ in overall performance on the Information subtest. While cultural differences were associated with performance on specific questions, overall performance did not appear to be affected significantly by cultural factors. This supports the utilization of the WISC- $R$ with the Canadian English-speaking population. On the other hand, a significant difference between the mean performance scores on the Digits Forward sec-

\section{Table 1}

Means, Standard Deviations and $t$ Tests for Independent Samples of 30 American and 30 Canadian Subjects on Information and Digit Span Subtests

\begin{tabular}{|c|c|c|c|c|c|c|}
\hline \multirow[b]{2}{*}{ Subtest } & \multicolumn{2}{|c|}{ Mean } & \multicolumn{2}{|c|}{ S.D. } & \multirow[b]{2}{*}{$t$} & \multirow[b]{2}{*}{$\mathrm{p}$} \\
\hline & U.S. & Can. & U.S. & Can. & & \\
\hline $\begin{array}{l}\text { Information } \\
\text { Digit Span Total } \\
\text { Digit Span Forward } \\
\text { Digit Span Backward }\end{array}$ & $\begin{array}{r}12.43 \\
9.47 \\
5.40 \\
4.03\end{array}$ & $\begin{array}{r}12.03 \\
11.20 \\
6.93 \\
4.27\end{array}$ & $\begin{array}{l}2.49 \\
2.06 \\
1.58 \\
1.17\end{array}$ & $\begin{array}{l}2.57 \\
2.96 \\
1.86 \\
1.50\end{array}$ & $\begin{array}{r}.60 \\
2.58 \\
3.40 \\
.66\end{array}$ & $\begin{array}{l}\text { ns } \\
.05 \\
.01 \\
\text { ns }\end{array}$ \\
\hline
\end{tabular}


tion of the Digit Span subtest suggests that Canadian children's attention on this task may be generally better than that of American children. In this respect, the utilization of the WISC-R with Canadian children may be questioned on the basis of these apparent cultural differences.

Cultural influences are the result of differences in the subject's experiences. The culturally biased questions in the Information subtest are biased because members of one society have experiences which are more related to the questions than members of the other society. For example, the knowledge that American inventor Thomas Edison invented the electric light bulb was known more frequently by American children because it is emphasized more frequently in American than Canadian schools. On the other hand, Canadian children knew that "a calf' was the name for a baby cow significantly more than American children. This may be due to the Canadian subjects' coming from a higher percentage of farming families. The question, "How many pennies make a nickel?" may have been more difficult for Canadian children because they use the word "cent" instead of the word "penny."

The results of the Digits Forward scores suggest that Canadian children may attend, or be oriented, to this task better than their American counterparts. It may be that differences in the two schools' academic programs are a contributing factor. Because of special federal funding, American schools include many supplementary programs such as resource rooms, remedial math, and reading classes. It is possible that because American children routinely work with a variety of adults everyday and are frequently tested individually in the supplementary classes, the test might not have been either as motivating or as anxiety evoking. On the other hand, Canadian children do not have the variety of supplementary programs and seldom are tested by anyone aside from their present teacher. The novel situation of being tested by an outside examiner may have been more motivating and may have resulted in their displaying better attention and performance on the task.

While this study does not establish any general conclusions about differences between American and Canadian students, it suggests that when the WISC-R is used with Canadian children, their experiences may influence their scores on some subtests. But the nature of the influence is not necessarily as might be predicted. More specifically, it is not necessarily true that Canadian children will score lower on certain subtests due to a deficit of information more common to American children. Rather, Canadian children might differ from their American counterparts as a function of their experiences with standardized tests. That is, differences may be emotional and motivational rather than cognitive and intellectual.

At this point, further research is indicated to address these possibilities, and it would be particularly useful to conduct studies in various locales. But until this research is conducted, examiners should interpret with caution the scores of Canadian children on the WISC-R or quite probably on other similar standardized tests. Perhaps the most direct way to address this issue is to standardize the WISC-R on a sample of Canadian children.

\section{References}

Anastasi, A. Psychology, psychologists, and psychological testing. American Psychologist, 1967, 22, 297-306.

Anastasi. A. Psychological testing. New York: Macmillan, 1976.

Brim, O. G. American attitudes toward intelligence tests. American Psychologist, 1965, 20, 125-130.

Census of Canada, 1971. Population-general characteristics. Toronto: Statistics Canada, 1971.

Deutsch, M., Fishman, J. A., Kogan, L., North, R., \& Whiteman, M. Guidelines for testing minority group children. Journal of Social lssues, 1964, 20, 129-145.

Glasser, A. J., \& Zimmerman, I. L. Clinical interpretation of the Wechsler Intelligence Scale for Children. New York: Grune \& Stratton, 1967. 
Jensen, A. R. Another look at culture-fair testing. In J. Hellmuth (Ed.), Disadvantaged child. (Vol. 3). New York: Brunner/Mazel, 1970.

Katz, J. Education in Canada. Connecticut: Archon Books, 1974.

Liddle, G. P. The school psychologists' role with culturally handicapped. In J. F. Magary (Ed.), School psychological services in theory and practice. Englewood Cliffs, NJ: Prentice-Hall, 1967.

Sattler, J.M. Assessment of children's intelligence. Philadelphia, PA: W. B. Saunders, 1974.

Welboum, P. Contemporary issues in Canadian education. Montreal: Holt, Rinehart, \& Winston of Canada, Ltd., 1972.
Wechsler, David. WISC-R manual. New York: The Psychological Corporation, 1974.

Williams, R. L. From dehumanization to black intellectual genocide: A rejoinder. Clinical Child Psychology Newsletter, 1970, 9. 6-7.

\section{Author's Address}

Requests for reprints or further information should be sent to Robert J. Griffore, Department of Urban and Metropolitan Studies, Michigan State University, East Lansing, MI 48823. 